\author{
Franco Bernasconi* \\ Eduardo Chávez Molina** \\ Georgina Di Paolo *** \\ José Javier Rodríguez de la Fuente ${ }^{* * * *}$
}

\title{
CAPÍTULO 1. LA CIUDAD DE BUENOS AIRES BAJO OBSERVACIÓN
}

\section{LA CIUDAD A TRAVÉS DE LOS OJOS DEL ARTE}

Buenos Aires se ha constituido, para nuestro estudio, en el epicentro de los análisis sobre los diferentes aspectos que dan cuenta de su estructura social, las condiciones de la desigualdad social, las posibilidades de movilidad social y los aspectos que hacen el contexto cultural y económico insoslayable en la forma posible de estudiarla.

Buenos Aires acapara una atracción particular por los indicadores sociales que la caracterizan, y por la centralidad como ámbito de despliegue artístico e intelectual. Es desde esa particularidad que iniciamos este capítulo, tratando de mostrar a qué ciudad nos acercamos cuando observamos campos específicos del acontecer social.

Nuestra presentación de la ciudad es a retazos, como componentes de un rompecabezas fragmentario, pero que permite perfilar la figura a completar y los rasgos sobresalientes de su propia incompletitud.

\footnotetext{
* IIGG-UBA.

** IIGG-UBA/UNMdP

*** IIGG-UBA.

**** IIGG-UBA.
} 
Sin ser un análisis exhaustivo, presentamos estas primeras páginas como un recorrido de la impronta artística de la ciudad, sus indicadores sociales, y el panorama de la estructura social que visualizaremos a continuación.

La sociedad siempre ha reflejado en el arte sus distintas formas de vida. Desde las pinturas rupestres del Paleolítico hasta la cinematografía moderna, las personas han buscado diversas maneras de expresar sus conflictos y sus anhelos para compartirlos con otros. Y, muchas veces, estas manifestaciones culturales dan mejor cuenta de las condiciones reales de su existencia que lo que pueden lograr un trabajo de ciencias sociales o los fríos números de la estadística. Por ello recorreremos las variadas formas en que el arte de y sobre la Ciudad de Buenos Aires han retratado las experiencias vitales de las porteñas y los porteños, para reconocer una parte sensible de quienes han habitado esta urbe en los últimos siglos.

Durante la primera mitad del siglo XIX, la forma de arte más extendida para mostrar a la ciudad fue la pintura ${ }^{1}$. Considerada América como un lugar exótico para los europeos, surgieron los llamados "artistas viajeros" que venían del Viejo Continente para pintar las particularidades de los paisajes y las personas autóctonas, para luego grabar en álbumes que permitían una comercialización masiva.

Es, sobre todo, gracias a los retratos y las vistas urbanas de artistas como Vidal, Pellegrini o Bacle que hoy día tenemos acceso a algunas de las primeras imágenes de la Ciudad de Buenos Aires en los tiempos de la incipiente nación, con su Cabildo, su Plaza de Mayo, su fuerte y su mercado, entre otros espacios de sociabilidad. Siguiendo su influencia, Carlos Morel, considerado el primer pintor argentino, buscó retratar lo que hace única a la ciudad, y así lo demuestran sus trabajos sobre las calles porteñas, aunque su obra estuviera más bien enfocada en retratar las tierras pampeanas. Se abría, sin embargo, una tradición, en la que los artistas locales comenzaban a poner el ojo en los personajes.

La aparición de la fotografía en la segunda mitad del siglo no sería un cambio radical pues, más allá de la novedad técnica, los temas retratados siguieron siendo los mismos y se demorarían varios años hasta que dejaron de representarse paisajes y retratos. Lo que sí renovó los aires de la escena artística fue la influencia de algunos estilos europeos como el romanticismo y el realismo, que hicieron volcar a los pintores porteños hacia distintas problemáticas sociales.

1 Las referencias artísticas mencionadas en este apartado se basan, fundamentalmente, en una entrevista realizada a Mario Orione, licenciado en Historia de las Artes (UBA). 
Con una mirada crítica, muchos de ellos comenzaron a mostrar las historias y los sentimientos de hombres y mujeres que vivían efectivamente la cotidianeidad de la ciudad. Una de las pinturas pioneras y más relevantes del período fue Sin pan y sin trabajo (Ernesto de la Cárcova, 1894), que presenta la escena de un trabajador desempleado junto a su familia en una situación económica precaria, condición común a muchos de los inmigrantes de la Buenos Aires de fines de siglo.

Ya en el siglo XX esta tendencia tomaría más fuerza, ya que las problemáticas sociales fueron tomadas por distintas corrientes de vanguardia provenientes de la literatura, la música, la pintura y el grabado. Esto fue perfectamente sintetizado por el "Grupo de Boedo", compuesto por artistas de esas disciplinas y, generalmente, vinculados al pensamiento de izquierda, reconociéndose entre ellos algunos de la talla del escritor Roberto Arlt.

Seguidos por su deseo de vincularse al recientemente surgido movimiento obrero, estos artistas asumieron los dramas de este nuevo grupo social como propios y buscaron retratar la explotación y las injusticias sociales para concientizar a los obreros de su situación común y fomentar su organización. Es así como encontramos entre sus temáticas más trabajadas, las precarias condiciones de vida de la clase obrera (sus deterioradas viviendas, sus conventillos, sus lugares de esparcimiento), donde es notable el hincapié hecho en los sufrimientos a los que se veían sometidos los desposeídos.

\section{EL CINE QUE RETRATA LA CIUDAD}

El cine ha dejado huellas imborrables en su retrato de la ciudad a través de los años. Ha mostrado en forma continua los vaivenes, los conflictos y las condiciones de vida de sus habitantes, dejando una identidad propia en su forma de señalar la vida de las porteñas y los porteños, nativos y afincados. No presentaremos aquí un recorrido exhaustivo sino, más bien, una invitación a entrever los rostros, las calles, los edificios y las cotidianidades porteñas a través de la lente de algunos de los cineastas más significativos de la historia argentina.

No puede comenzar este camino por otro lado que no sea la Buenos Aires de principios de siglo XX, una ciudad inundada por inmigrantes de diversos lugares del mundo que, en su mezcla, produjeron una cultura novedosa y muy rica. De allí saldría el lunfardo, que Julián Centeya supo darle sistematicidad, y el tango que, junto con el compadrito, ese joven de barrio bajo, provocador y corajudo, como figura característica de la época, tan bien retratado en la clásica Un guapo del 900 (1960) de Leopoldo Torre Nilsson. Allí se puede ver el 
cruce de ese "bajo mundo" con el otro, el mundo de la alta política conservadora, no exento de polémica, como lo refleja la muerte de un famoso congresista en Asesinato en el Senado de la Nación (1984) de Juan José Jusid.

Rápidamente, la ciudad se convertiría en la pujante capital de un país en pleno despliegue, y con una producción cultural que la haría convertirse en el epicentro de los artistas nacionales. El centro, así, se convirtió en el lugar codiciado por todos, tal como dejan ver El cantor de Buenos Aires (1940) de Julio Irigoyen o Así es Buenos Aires (1971) de Emilio Vieyra. Pero no eran sólo los artistas quienes deseaban llegar a la ciudad.

El impulso industrialista iniciado a mitad de los 40 , gracias a un fuerte apoyo estatal, necesitaba brazos que accionaran su maquinaria: de distintas partes del país acudieron importantes cantidades de personas para responder a ese llamado esperanzador. En su mayoría de origen rural, los migrantes se asentaron en la ciudad y sus alrededores, como el obrero metalúrgico de La voz de mi ciudad (1953) de Tulio Demicheli.

Luego de una década de profundas transformaciones tanto políticas como sociales y culturales, la Revolución Libertadora del año 1955 produciría un cambio en el perfil de Buenos Aires, particularmente, que ya comienza a configurarse como una ciudad abocada a los servicios. En el cine, la ciudad continuó siendo retratada las más de las veces como esa capital artística, donde todo lo importante parecía suceder alrededor del mundo del teatro o del tango, como se muestra en films como Estrellas de Buenos Aires (1956) de Kurt Land y Buenas noches, Buenos Aires (1964) de Hugo del Carril. Quizás una de las excepciones más notables es Breve cielo (1969 de David José Kohon), que retrata de manera íntima a los jóvenes marginales y su relación con el sexo (Manrupe y Portela, 2001), tema todavía tabú para la pantalla grande, en especial, después de años de censura artística.

Con respecto a los años 70, la cinematografía cambiaría su perspectiva y se volcaría hacia los hechos fundamentales de la vida política en la ciudad, especialmente tras el horror de la última dictadura cívico-militar (1976-1983). Clásicos como Garage Olimpo (1999) de Marco Bechis y La historia oficial (1985) de Luis Puenzo retrataron sin filtro la peor cara humana con la represión estatal, los detenidosdesaparecidos y el robo de bebés. En el año 83, con la apertura democrática, comienza un proceso de normalización política que, sin embargo, no sería fácil para los sobrevivientes de la dictadura, como Mastronardi en El mismo amor, la misma lluvia (1999), de Juan José Campanella, un exiliado político que no encuentra su lugar en la nueva ciudad, todavía cruel frente a un pasado con heridas abiertas.

Los 80 también serían años de ebullición cultural, de salida a la luz de movimientos que no podían alzar la cabeza por la censura. La po- 
blación gay, por ejemplo, vivió una fuerte explosión en la posdictadura, tal como lo retrata la reciente Muerte en Buenos Aires (2014) de Natalia Meta; y el rock se convirtió en el movimiento de la juventud, con la discoteca Cemento (2017) como epicentro de la música porteña, como lo demuestra el reciente documental. No obstante, se estaba gestando subterráneamente un ciclo de empobrecimiento general de la población, que vemos encarnados en los constantes problemas económicos de Jorge en la temprana Esperando la carroza (1985) de Alejandro Doria.

Los problemas financieros no se detendrían en la siguiente década sino que, más bien, se agravarían. Momento de crisis identitarias, los años 90 marcan la concreción del plan de ajuste y reestructuración neoliberal iniciado con la última dictadura, con terribles repercusiones en el plano económico y social. Como vemos en Buenos Aires viceversa (1996) de Alejandro Agresti o en Esperando al Mesías (2000) de Daniel Burman, los jóvenes están desorientados y viven en un constante tropezón existencial, acechados por el descreimiento (bien fundado) en un futuro mejor.

El Estado se ha corrido de su papel de interventor de la economía y aparecen en la estructura social una gran cantidad de sujetos que no pueden ser absorbidos por el mercado de trabajo y pasan a formar parte de la masa marginada de la población. Los desempleados crónicos y los "busca" aparecen en escena, intentando sobrevivir a como dé lugar, incluso si eso implica el camino delictivo, como observamos en Marcos y Juan, los carismáticos estafadores de la clásica Nueve reinas (2000) de Fabián Bielinsky, o en la banda de amigos de Pizza, birra, faso (1998) de Adrián Caetano y Bruno Stagnaro, hoy considerada de culto.

Todo este proceso desembocaría en los terribles hechos de diciembre del 2001, cuando una movilización popular provocó la caída de un gobierno en el contexto de una crisis económica que se hacía cada vez más evidente a los ojos de la ciudadanía. El cine reflejó claramente los trastocamientos producidos en la sociedad, donde una señora acostumbrada a un buen pasar ya no puede pagarle a su empleada doméstica, en Cama adentro (2005) de Jorge Gaggero, o hasta el hijo de una senadora puede terminar consumiendo las drogas de la peor calidad en un barrio marginal de la ciudad, en Paco (2010) de Diego Rafecas.

Si bien la primera década de los 2000 marcaría una recuperación económica y social, la Buenos Aires del siglo XXI le debe mucho a las décadas pasadas. Se trata de una Buenos Aires marcada por la extrema desigualdad, donde la pobreza se ha instalado como paisaje cotidiano y donde, como en tantas ciudades latinoamericanas, se ha desarrollado un entramado donde los gobiernos se disputan el poder con el narcotráfico y la iglesia hacia el interior de los barrios marginales, trama principal de Elefante blanco (2012) de Pablo Trapero. 
Se trata también de una Buenos Aires vivida como una típica urbe contemporánea, donde la mayoría de la población se ve asediada por la soledad, la neurosis y la dependencia del recientemente abierto mundo virtual, como los protagonistas de Medianeras (2011) de Gustavo Taretto. Sin embargo, la particularidad de la Buenos Aires actual está dada por el constante desorden, la imprevisibilidad y la ira contenida por parte de los ciudadanos que la transitan a diario. La excesiva aglomeración combinada con malos servicios de transporte y los constantes cortes de calle, producto de su centralidad nacional para ejercer el derecho a la demanda cívica, la convierten en un blanco perfecto para un cine que retrata a la perfección esos conflictos urbanos. Películas recientes, como Carancho (2010) de Pablo Trapero, La vendedora de fósforos (2017) de Alejo Moguillansky o algunas de las historias presentes en Relatos Salvajes (2014) de Damián Szifron, nos muestran el sufrimiento al que se ven sometidos sus habitantes día a día, donde todo parece estar a punto de estallar todo el tiempo y donde, a veces, lo hace.

Eclipsado por los cambios estructurales, la ciudad muestra un perfil no sólo arquitectónico, sino social, de una complejidad particular, que es lo que a continuación vamos a observar, los indicadores sociales sobre los que se asienta este trabajo y los capítulos que continúan en este libro.

\section{LA ESPECIFICIDAD DE LA CIUDAD AUTÓNOMA DE BUENOS AIRES: ESTRUCTURA SOCIAL Y DESIGUALDADES A TRAVÉS DE LOS INDICADORES ${ }^{2}$}

La Ciudad de Buenos Aires puede ser visualizada hoy en día según varios aspectos de la vida social que permiten una apreciación general, pero ajustada a información estadística, sobre determinadas dimensiones que caracterizan, tanto sus condiciones económicas, como también la impronta pública de los servicios sociales que presta y el sector privado de fuerte impronta en la capital de la República.

Esta conforma uno de los 24 estados autogobernados que constituyen la República Argentina. Al mismo tiempo, se diferencia de los 23 restantes debido a que funciona como capital federal del país. Su superficie es de 203,2 km², con una densidad de 151.101 habitantes por $\mathrm{km}^{2} \mathrm{y}$ forma parte del Aglomerado Gran Buenos Aires (AGBA), que se define como el área geográfica delimitada por la "envolvente de población" o lo que también puede llamarse "mancha urbana" (INDEC, 2003b: 4) (ver Mapa 1), y que representa el 6,8\% del total país.

2 Apartado basado parcialmente en el capítulo IV de la tesis de Doctorado de José Rodríguez de la Fuente. 
Siguiendo las divisiones administrativas de los partidos ${ }^{3}$ que circundan a la ciudad, el Gran Buenos Aires (GBA) cuatriplica en cantidad de población a la CABA (2.890.151 habitantes versus 12.806.866, según datos del Censo 2010). Sin embargo, es necesario aclarar que la unidad GBA invisibiliza una clara heterogeneidad existente entre la CABA y los partidos del Conurbano en la mayor parte de las dimensiones que pueden estudiarse, incluida la conformación de la estructura poblacional (De la Torre, 2013: 5). Política y administrativamente, la ciudad se divide en 15 comunas $^{4}$, es decir, unidades descentralizadas que pueden abarcar más de un barrio ${ }^{5}$ (ver Tabla 1 ).

Mapa 1. Ciudad Autónoma de Buenos Aires, Gran Buenos Aires y Aglomerado Gran Buenos Aires

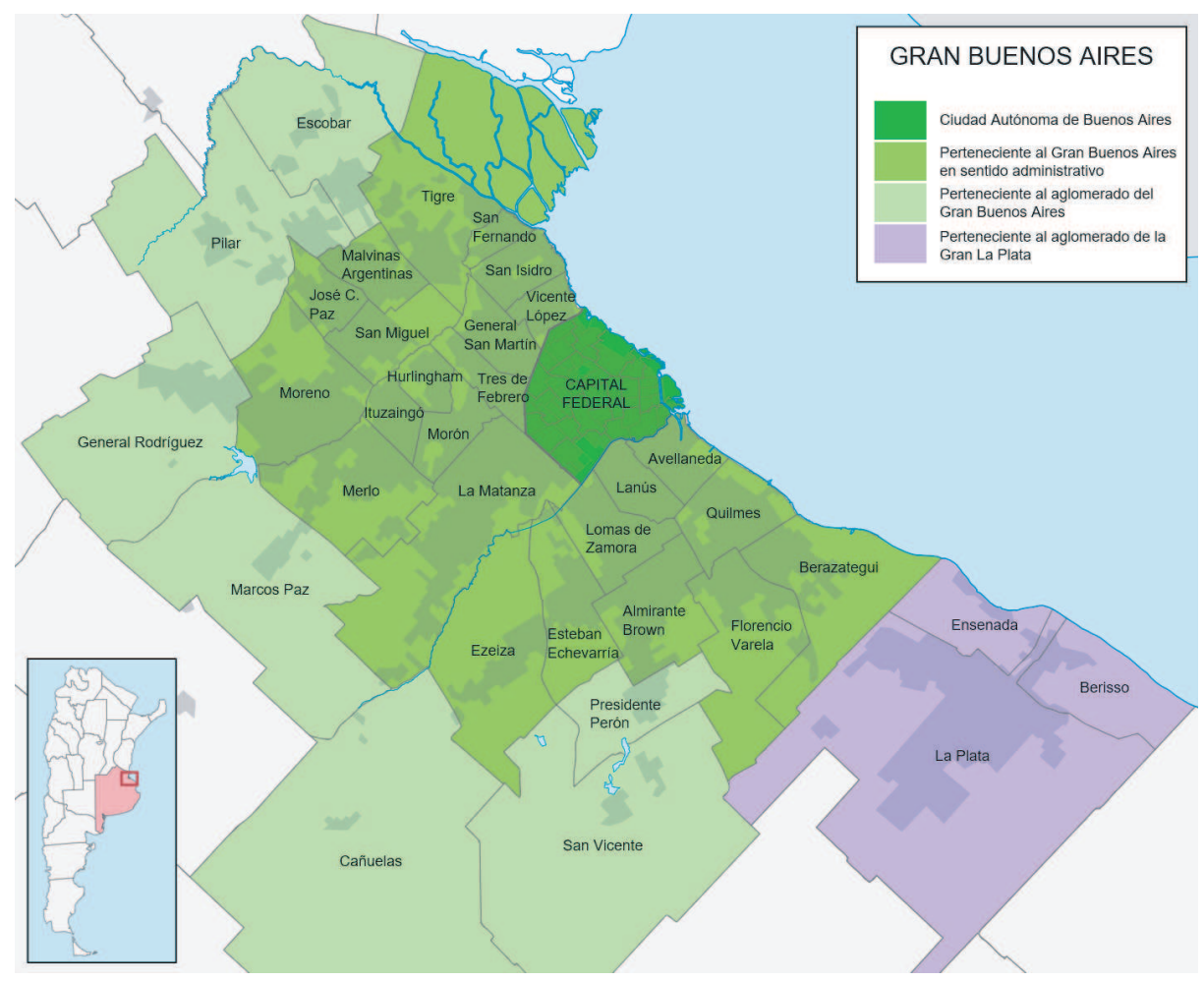

Fuente: https://es.wikipedia.org/wiki/Archivo:Mapa_de_la_Gran_Buenos_Aires.svg

3 El GBA está compuesto por la Ciudad de Buenos Aires y los 24 partidos que la rodean (INDEC, 2003a).

4 A partir de la sanción de la ley 1777, sancionada en 2005.

5 En total, el Gobierno de la CABA reconoce la existencia de 48 barrios porteños (ver http://www.buenosaires.gob.ar/laciudad/barrios). 
Tabla 1. Distribución de barrios por comuna. CABA

\begin{tabular}{c|l}
\hline Comuna & \multicolumn{1}{c}{ Barrio } \\
\hline 1 & Constitución, Monserrat, Puerto Madero, Retiro, San Nicolás, San Telmo \\
\hline 2 & Recoleta \\
\hline 3 & Balvanera, San Cristóbal \\
\hline 4 & Barracas, La Boca, Nueva Pompeya, Parque Patricios \\
\hline 5 & Almagro, Boedo \\
\hline 6 & Caballito \\
\hline 7 & Flores, Parque Chacabuco \\
\hline 8 & Villa Lugano, Villa Riachuelo, Villa Soldati \\
\hline 9 & Liniers, Mataderos, Parque Avellaneda \\
\hline 10 & Floresta, Monte Castro, Vélez Sarsfield, Versalles, Villa Luro, Villa Real \\
\hline 12 & Villa Del Parque, Villa Devoto, Villa Gral. Mitre, Villa Santa Rita \\
\hline 13 & Coghlan, Saavedra, Villa Pueyrredón, Villa Urquiza \\
\hline 14 & Belgrano, Colegiales, Núñez \\
\hline 15 & Palermo \\
\hline
\end{tabular}

Por su parte, la ciudad, en tanto capital del conjunto nacional, dispone de cierta densidad política, económica y social que la diferencian de otras ciudades y regiones del país, específicamente respecto al nivel de vida (Velázquez, 2007). En este sentido,puede ser caracterizada como una "ciudad global" en la medida que: 1) concentra funciones de comando; 2) es un sitio de producción posindustrial para las industrias líderes, financieras y de servicios especializados; y 3) funcionan como mercados transnacionales donde las empresas y los gobiernos compran instrumentos financieros y servicios especializados (Sassen, 1998: 7). En términos específicos, la transformación en una "ciudad global" se evidenció en la ampliación del comercio, la modernización tecnológica, el desarrollo de nuevas ocupaciones profesionales, el crecimiento de inversiones transnacionales y la terciarización de las actividades más importantes (Obradovich, 2010: 15); pero, asimismo, actúa bajo la lógica empresarial, configurando nuevas relaciones de empleo, generalmente en los últimos años de características precarias, ya sean descentralizadas, subcontratadas o formatos encubiertos como el empleo colaborativo, que diseña panoramas novedosos en relación a todo el país. En conjunción con esta mirada, otros autores han señalado el proceso de transformación de la CABA como una "ciudad neoliberal" (Pírez, 2016; 
Rodríguez, Rodríguez y Zapata, 2015) a partir de finales de los años 70, ante la desarticulación y descrédito producido sobre las instituciones y políticas propias del Estado de Bienestar. Estás rupturas generadas en el plano económico tuvieron sus consecuencias en el ámbito urbano a partir de una pérdida de la "solvencia popular", en tanto forma desmercantilizada de acceso y reproducción del hábitat, en términos de liberalización del mercado inmobiliario como respecto a la privatización de los servicios públicos (Pírez, 2016) por mencionar algunos. Dentro de las principales políticas que transformaron el espacio urbano imprimiéndole una impronta neoliberal, podemos citar: la liberalización de alquileres, la erradicación de villas de la ciudad, la implementación de un nuevo Código de Planeamiento Urbano, las expropiaciones para la construcción de autopistas urbanas, la relocalización de industrias, entre otras (Oszlak, 1988, 1991; Rodríguez et al., 2015).

\subsection{ESTRUCTURA SOCIODEMOGRÁFICA Y PRODUCTIVA DE LA CABA ${ }^{6}$}

Una primera aproximación a la comprensión del carácter que asume la estructura social porteña puede basarse a partir del análisis de la distribución de la población por sexo y edad.

Gráfico 1. Estructura población por sexo y edad. CABA 2010

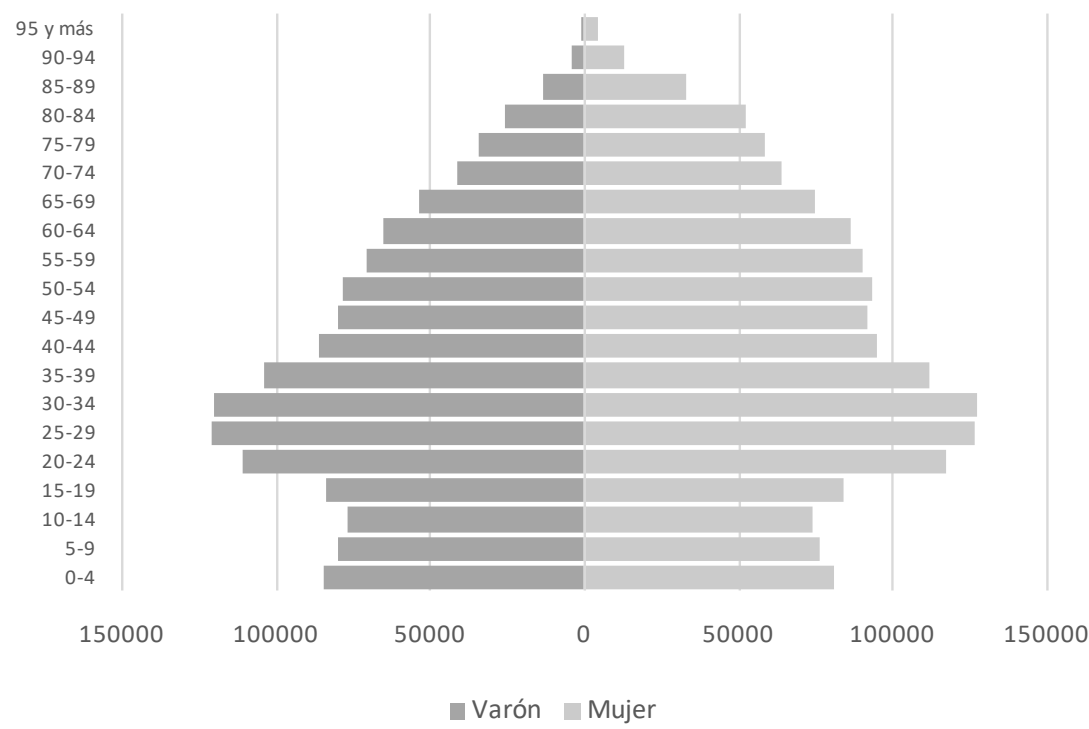

Fuente: elaboración propia en base Censo Nacional de Población, Hogares y Viviendas 2010 (INDEC). N = 2890151.

6 Algunos aspectos vinculados a la estructura socioeconómica de la CABA pueden verse en el capítulo 3 de este libro. 
Gráfico 2. Estructura población por sexo y edad. GBA 2010

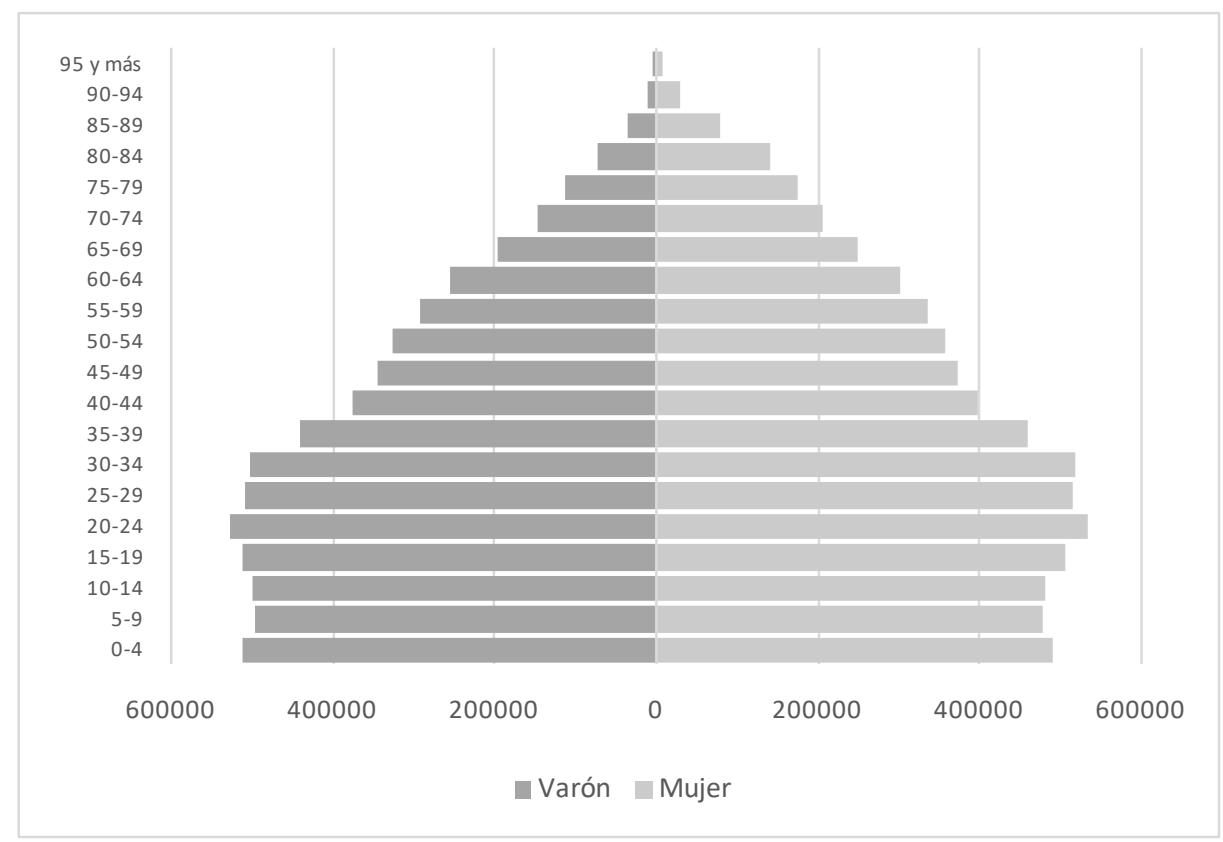

Fuente: elaboración propia en base Censo Nacional de Población, Hogares y Viviendas 2010 (INDEC). N = 12806866.

Como podemos observar en el Gráfico 1, la estructura poblacional de la CABA dista de presentar un formato piramidal, característico del GBA (ver Gráfico 2) o del total país. Por el contrario, su contracción en el tramo etario de 0 a 19 años y su ampliación en el tramo de 60 años y más (específicamente para las mujeres), ilustra la composición de una ciudad con población envejecida. En términos comparativos, la CABA presenta la tasa más alta en el país de envejecimiento al existir, para 2010, una población de 65 años y más de aproximadamente un 16\%, alcanzando las mujeres un pico del 19\% (Redondo, 2012: 24). Si bien el proceso de envejecimiento poblacional aumenta progresivamente desde inicios del siglo XX, es en la década del 60 donde ya presenta un nivel de, aproximadamente, 50 adultos mayores por cada 100 niños, alcanzado en 2010 la paridad entre ambos grupos poblacionales (DGEyC-GCBA, 2013: 15). En cambio, para el GBA, si bien ya empieza a ensancharse la pirámide (aproximándose a un formato de "campana”), al crecer la franja de los 20 a 34 años, aún presenta un importante núcleo de población joven. 
Un segundo aspecto para la comprensión de la estructura social de la CABA resulta del análisis de su estructura socio-productiva. La dimensión que nos permite un acercamiento a dicho aspecto es el estudio del peso que adquieren las distintas ramas de actividad en la economía de la CABA respecto al resto del país (Gráfico 3).

Gráfico 3. Porcentaje de participación en el PBG* por categoría de la ClaNAE**. CABA y Total país. 2013

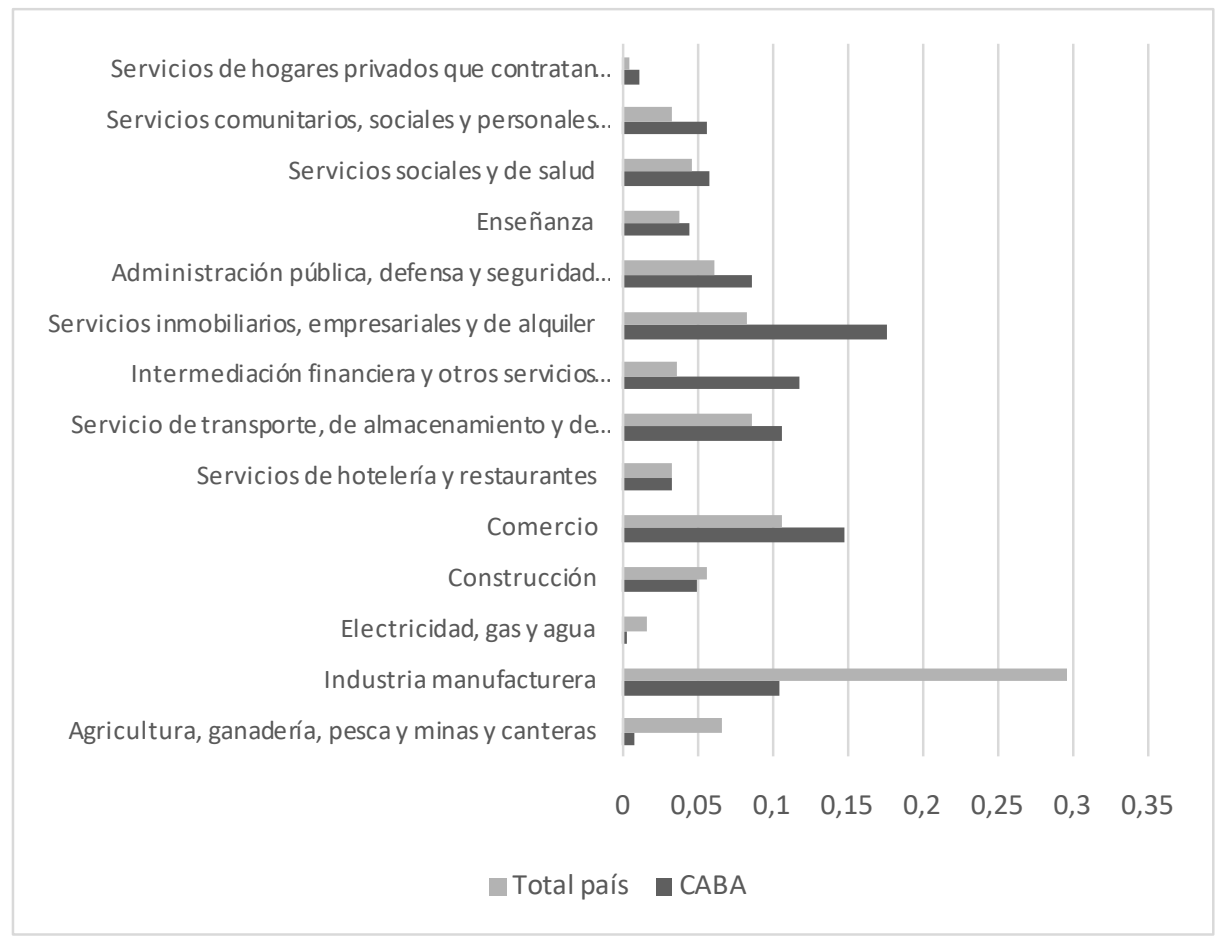

* PBG calculado a precios básicos.

** Clasificador Nacional de Actividades Económicas.

Fuente: elaboración propia en base a datos de la Dirección General de Estadística y Censos (Ministerio de Hacienda GCBA) e INDEC.

El PBG por actividad económica nos permite observar qué ramas de la economía resultan más productivas, tanto en la CABA como en el total país. El producto geográfico bruto (PGB) "es un cálculo que permite medir la riqueza de una región mediante la estimación 
del valor de todos los bienes y servicios que se producen dentro de sus fronteras durante un año" (Buenos Aires en números, DGEyCGCBA, 2017). Hacia 2015 se registraron 1.103 .722 millones de pesos (a precios corrientes) de los cuales un tercio se correspondieron a la actividad de servicios inmobiliarios, empresariales y de alquiler en suma a la rama de comercio. Desde 2005, el PGB fue creciendo año a año, con algunos descensos entre 2008 y 2009 para recomponerse en 2010;sin embargo, en 2014 experimentó una caída de 1,6\%, mientras que en 2015 se incrementó un 2,4\% (Anuario estadístico 2016, DGEyC-GCBA, 2016).

De este modo, rápidamente, podemos observar que la estructura productiva de la CABA se compone por un núcleo dinámico que agrupa a los servicios financieros, inmobiliarios y empresariales, seguido, en menor medida, por el sector de transporte, comunicaciones, comercio y la administración pública (Obradovich, 2010: 16). Por su parte, el bajo peso de la industria manufacturera, respecto a su perfomance para el total nacional (aproximadamente unos 20 p.p. de diferencia), refuerza no sólo el sesgo de la CABA como "ciudad de servicios", sino que también da cuenta del saldo que ha dejado en la estructura productiva porteña el proceso de relocalización territorial de las industrias, quedando en la ciudad únicamente las sedes de las mismas con funciones altamente especializadas (Oszlak, 1988, 1991; Sassen, 1998: 15, 20).

En lo que respecta a las exportaciones, la Ciudad de Buenos Aires alcanzó unos 318 millones de dólares en la exportación de bienes, de los cuales poco más del $70 \%$ corresponde a manufacturas de origen industrial, tales como productos químicos, cerámicos y textiles; seguido de manufacturas de origen agropecuario, así como pieles y cueros, entre otros. Los principales destinos de dichas manufacturas son países de la Unión Europea y el Mercosur.

La inflación, por otra parte, a través del indicado Índice de Precios al Consumidor de la Ciudad de Buenos Aires (IPCBA), se estima alcanzó un promedio del $41 \%$ durante el 2016 respecto al año anterior (Buenos Aires en números, DGEyC-GCBA, 2017).

\subsection{INDICADORES GENERALES SOCIOECONÓMICOS DE LA CIUDAD AUTÓNOMA DE BUENOS AIRES}

El análisis de la estructura sociodemográfica y productiva de la ciudad puede complementarse con la evolución de ciertas dimensiones, que conforman lo que puede entenderse como "condiciones laborales", basadas en el empleo y la ocupación. Para esto analizaremos 
algunos aspectos que consideramos relevantes: mercado de trabajo, distribución del ingreso y hábitat.

En primer lugar, haremos un breve repaso respecto a la evolución de algunos indicadores centrales que permiten caracterizar las tendencias que transitó el mercado de trabajo en la CABA. Para esto se recurrirá al análisis de tres indicadores específicos: la tasa de empleo ${ }^{7}$, la tasa de desocupación ${ }^{8}$ y la tasa de informalidad ${ }^{9}$. Cada uno de estos indicadores es observado tanto para la población de 30 años o más, así como para la población total (mayor de 10 años).

Gráfico 4. Tasa de empleo. CABA 2004-2015

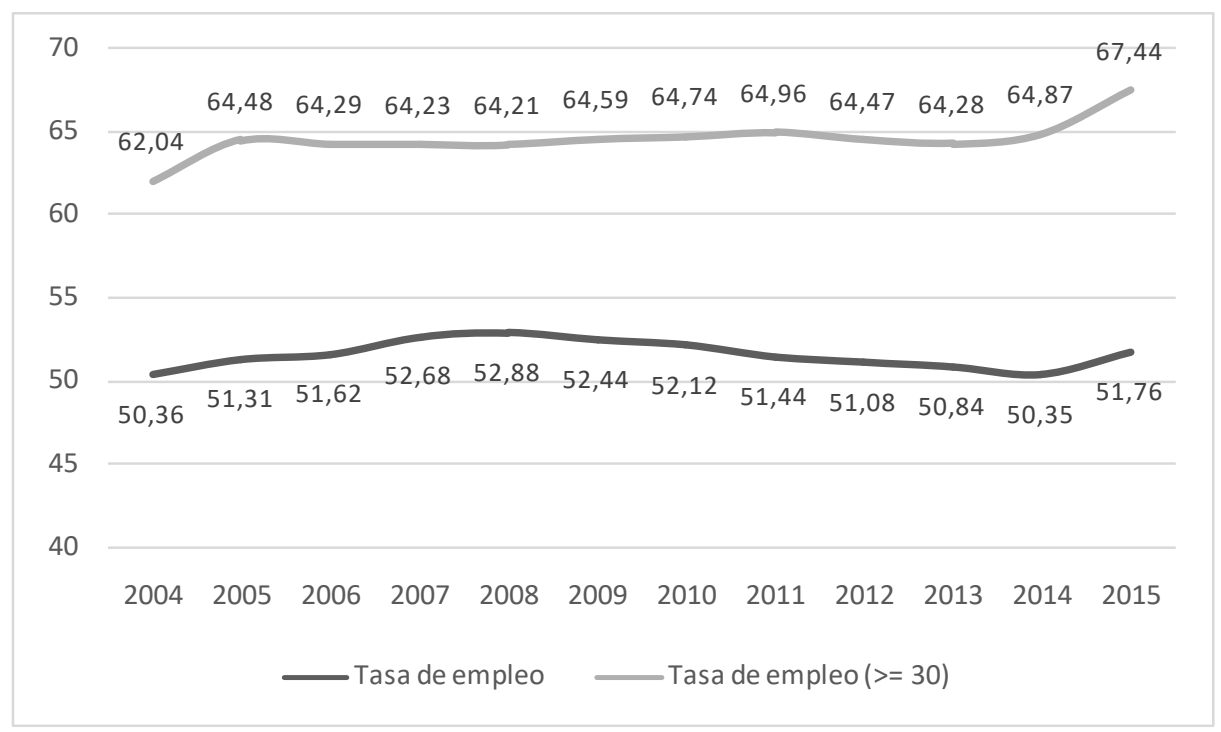

Fuente: elaboración propia en base a EAH - Dirección General de Estadística y Censos (Ministerio de Economía y Finanzas GCBA).

7 Porcentaje de la población ocupada (mayores de 10 años) con respecto a la población total.

8 Porcentaje de la población desocupada (mayores de 10 años) con respecto al total de la población económicamente activa.

9 Clasificamos como "trabajadores informales" a los individuos que se encuentran en las siguientes situaciones: 1) asalariados a los que no se le realizan descuentos jubilatorios; 2) empleadores o trabajadores por cuenta propia no calificados o de calificación operativa; y 3) trabajadores familiares. 
Gráfico 5. Tasa de desocupación. CABA 2004-2015

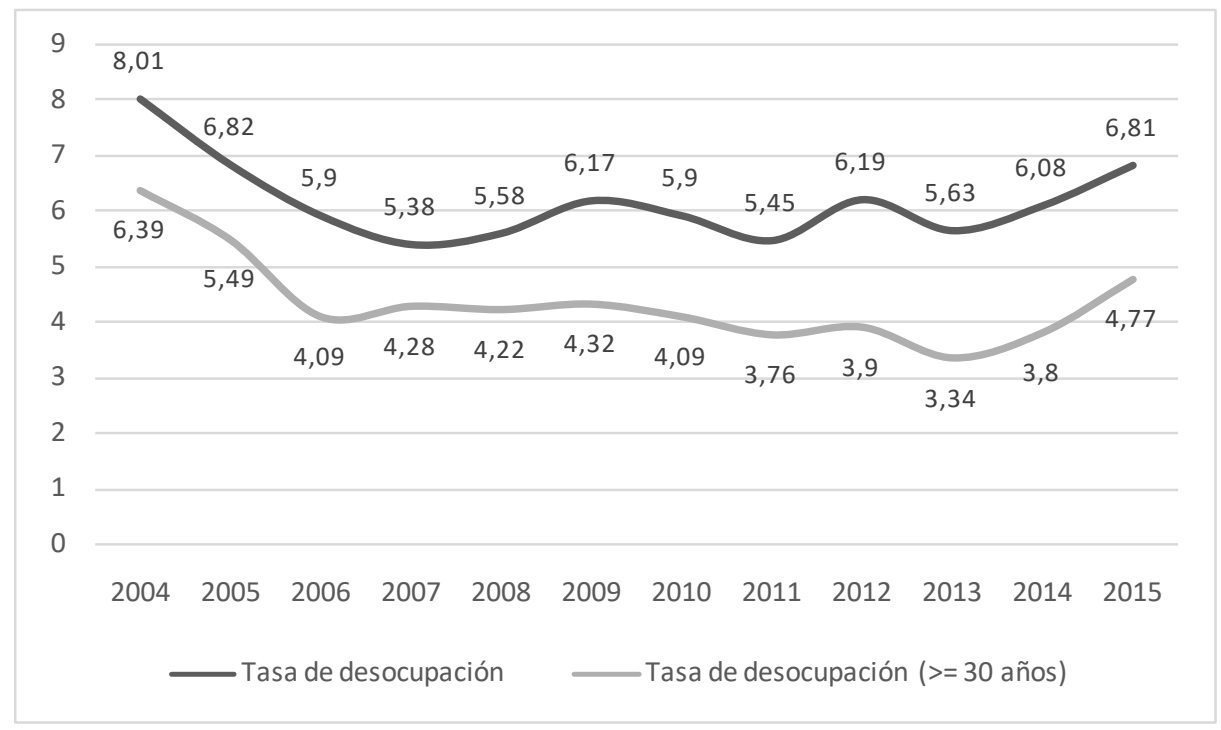

Fuente: elaboración propia en base a EAH - Dirección General de Estadística y Censos (Ministerio de Economía y Finanzas GCBA).

Gráfico 6. Tasa de informalidad. CABA 2004-2015

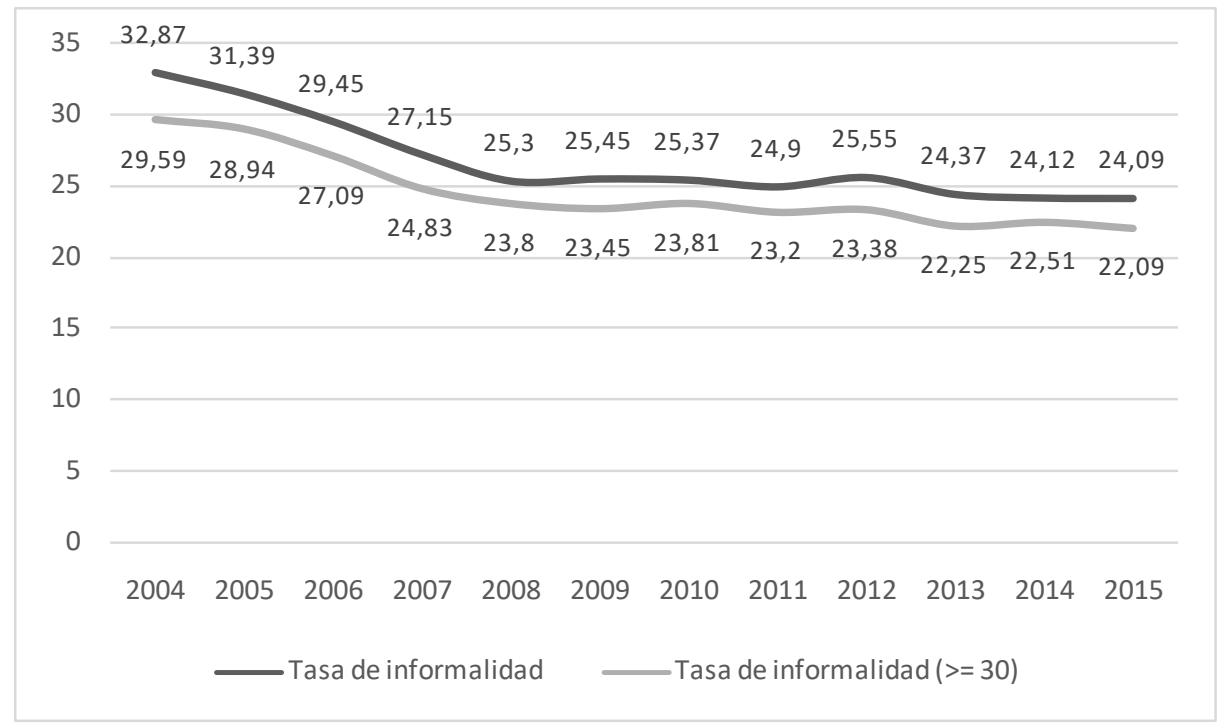

Fuente: elaboración propia en base a EAH - Dirección General de Estadística y Censos (Ministerio de Economía y Finanzas GCBA). 
En términos generales, la tasa de empleo (ver Gráfico 4) se mantuvo constante, con excepción de dos períodos de crecimiento: del 2004 al 2005 y del 2014 al 2015. En el primer período, producto de la reactivación económica pos 2001-2002, aumentó en casi 2,5 p.p., manteniéndose luego en el promedio de $64 \%$ hasta 2014. El segundo crecimiento experimentado hacia el final del período (también de 2,5 p.p. promedio) puede explicarse por el crecimiento de $2,1 \%$ que experimentó la economía nacional respecto al año anterior ${ }^{10}$. Por su parte, la tasa general de empleo (aquella que considera la ocupación para mayores de 10 años) siguió una tendencia más vinculada al ciclo económico, mostrando un importante crecimiento (2,5 p.p.) entre 2004 y 2008; pero decreciendo luego, llegando en 2014 a un nivel similar a 2004. Al igual que para los mayores de 30 años, en 2015 el empleo se revitaliza, volviendo la tasa a situarse a niveles de la década anterior $(51,8 \%)$.

La tasa de desocupación (ver Gráfico 5) se comportó de manera similar para ambas poblaciones y siguió la tendencia del ciclo económico: bajó fuertemente hasta 2006/2007; presentó un leve aumento (principalmente para la población total) en la coyuntura de la crisis financiera internacional (2008-2009); bajó nuevamente hasta 20112013, aumentado luego más de 1 punto hacia finales del período. Mientras que el promedio para la población mayor de 10 años fue de $6,2 \%$ de desocupación, para los mayores de 30 años fue considerablemente menor, $(4,4 \%)$.

Hacia 2016, aproximadamente el 50\% de los habitantes de la ciudad se encontraban ocupados, y la tasa de desocupación representaba un 9,8\% de la PEA. La situación de desempleo afecta mayormente a las mujeres $(11,7 \%)$ que a los varones (8\%) (Buenos Aires en números, DGEyC-GCBA, 2017).

En tercer lugar, la informalidad descendió considerablemente a lo largo del período, reduciéndose aproximadamente 7,5 p.p. entre puntas (ver Gráfico 6). Hasta 2008, en conjunción con el mayor dinamismo evidenciado en el resto de los indicadores laborales, el descenso fue considerable, entrando luego en una fase de amesetamiento. Hacia el final del período, si bien la informalidad continuó descendiendo, el impacto fue algo más relevante para el grupo poblacional mayor a 30 años, alcanzando un valor del $22 \%$.

Tomando en cuenta los dos últimos indicadores laborales, puede apreciarse que la crisis internacional de 2008 funcionó como un parte aguas respecto a las mejoras económicas (Kessler, 2014: 13). Asimismo, se puso

10 Ver https://www.indec.gob.ar/uploads/informesdeprensa/pib_03_16.pdf 
en evidencia que el objetivo de generar un proceso de industrialización, impulsado a partir de la política cambiaria y la aplicación de retenciones, si bien había rendido sus frutos en los anteriores cinco años, comenzaba a presentar ciertas limitaciones (CENDA, 2010: 80 ), principalmente, debido a que la capacidad instalada industrial estaba llegando al nivel de saturación. Particularmente, a los efectos de contrarrestar dichas insuficiencias, las políticas económicas, impulsadas a partir de 2008, tuvieron como finalidad (entre otras) sostener los niveles de bienestar conseguidos hasta el momento. Específicamente, respecto al mercado laboral, se implementó el Programa de Recuperación Productiva (REPRO), destinado a evitar despidos y reducciones salariales y la derivación de recursos a la obra pública, con el fin de generar empleo y hacer frente a la desaceleración del crecimiento económico (Varesi, 2011: 50).

Para medir la evolución de los ingresos en el período analizado, optamos por presentar el coeficiente de Gini a partir de los ingresos totales per cápita familiares y los ingresos laborales per cápita familiares $^{11}$ (ver Gráfico 7). De esta forma intentamos poder separar los impactos que tuvieron las políticas de transferencia de ingresos (Asignación Universal por Hijo -AUH-, moratoria jubilatoria, pensiones no contributivas, Ciudadanía Porteña ${ }^{12}$, etc.) en la disminución de la desigualdad de ingresos al interior de los hogares, de aquellas ligadas explícitamente a cambios específicos ocurridos en el mercado de trabajo. Asimismo, para medir dicha diferenciación se dibuja (en barras) la brecha laboral entre el cálculo de Gini total y el laboral.

11 Para el caso de la población total únicamente presentamos los ingresos totales per cápita familiares.

12 Es necesario aclarar que en la ciudad de Buenos Aires, desde el 2005, funciona el programa Ciudadanía Porteña. El programa dirige sus acciones a los hogares residentes en la ciudad en situación de pobreza, enfatizando su accionar en los de mayor vulnerabilidad. Entre estas características se destacan: la presencia de embarazadas, menores de 18 años, discapacitados y adultos mayores. En 2017 contaba con 142.266 beneficiarios (Sistema Integral de Coordinación de Políticas Sociales, 2017). 
Gráfico 7. Evolución del coeficiente de Gini a partir de ingresos per cápita familiares e ingresos laborales per cápita familiares. CABA 2004-2015

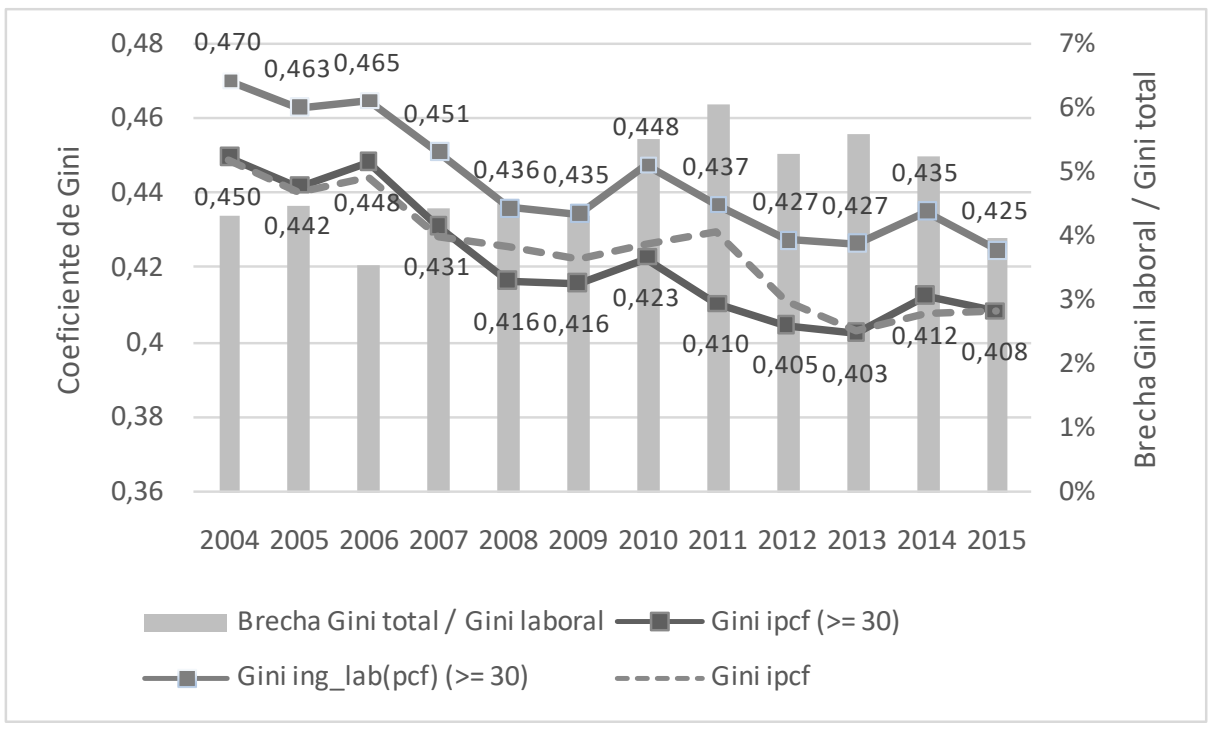

Fuente: elaboración propia en base a EAH - Dirección General de Estadística y Censos (Ministerio de Economía y Finanzas GCBA).

En este sentido, tres conclusiones pueden rescatarse de la lectura del Gráfico 7: 1) una tendencia general de disminución de la desigualdad de ingresos a lo largo del período; 2) rebotes que representan un aumento de la desigualdad, en las fases poscrisis 2008-2009, así como en el año 2014, producto de la fuerte devaluación de la moneda en un 14\% y su correlato en el incremento inflacionario ${ }^{13}$; y 3 ) un incremento de la brecha entre los dos tipos de mediciones a partir de 2010, señalando el impacto que las políticas de transferencia de ingresos reseñadas anteriormente tuvieron en la reducción de la desigualdad ${ }^{14}$, aunque dicha merma se haya

13 Según el IPC, que calcula la Dirección de Estadísticas y Censos de la Ciudad de Buenos Aires, el nivel de inflación general de 2014 trepó al 32,6\%, muy por encima del 23,9\% de 2013.

14 A partir de finales de 2009, la AUH compite en la ciudad de Buenos Aires con el programa Ciudadanía Porteña. Algunos autores (Asesoría General Tutelar, 2011; Bermúdez, Carmona Barrenechea y Royo, 2015) señalan, a partir de la merma de beneficiarios en el programa porteño, la transición de muchas familias a la AUHPS. 
visto reducida hacia el final del período, producto de la escalada inflacionaria.

Por otro lado, la vivienda, en tanto aspecto constitutivo del bienestar, es una dimensión poco estudiada (Carmona Barrenechea y Messina, 2015: 204). En este sentido, la discusión se ha reducido al estudio de las condiciones habitacionales, la informalidad urbana y al hábitat popular. Sin embargo, la situación habitacional de la CABA se diferencia radicalmente de la presentada en el conurbano, así como en otras grandes aglomeraciones del país: la infraestructura urbana de servicios cubre prácticamente la totalidad del territorio, concentrándose el déficit en los barrios no urbanizados de villas o asentamientos precarios (De la Torre, 2013: 7 $)^{15}$. Dos indicadores como el nivel de hacinamiento crítico $^{16}$ (Gráfico 8) y la calidad de conexión a servicios básicos ${ }^{17}$ (Gráfico 9), permiten ilustrar dicho fenómeno. En ambas dimensiones, la CABA presenta niveles bajos de condiciones habitacionales deficientes, respecto al promedio del total país.

15 Territorialmente, las zonas de mayor déficit en condiciones habitacionales se encuentran en la zona centro-sur (habitaciones en hoteles-pensiones e inquilinatos) y en la Comuna 1, donde se localizan algunas de las villas más pobladas y con mayor crecimiento (Villa 31 y 31 bis) (Rodríguez, Rodríguez, y Zapata, 2015).

16 Según INDEC, pueden considerarse con hacinamiento crítico a aquellos hogares con más de tres personas por cuarto ( Recuperado de https://www.indec.gob.ar/textos_glosario.asp?id=20.

17 Dicho concepto refiere al tipo de instalaciones con que cuentan las viviendas para su saneamiento. Para este indicador, se utilizan las variables procedencia del agua y tipo de desagüe. Las categorías de dicho indicador son: 1) calidad satisfactoria (refiere a las viviendas que disponen de agua a red pública y desagüe cloacal); calidad básica (describe la situación de aquellas viviendas que disponen de agua de red pública y el desagüe a pozo con cámara séptica); y 3) calidad insuficiente (engloba a las viviendas que no cumplen ninguna de las dos condiciones anteriores).Recuperado de https://redatam.indec.gob.ar/redarg/CENSOS/ CPV2010rad/Docs/base.pdf. 
Gráfico 8. Porcentaje de hogares con hacinamiento crítico. CABA y Total país.

$2001 / 2010$

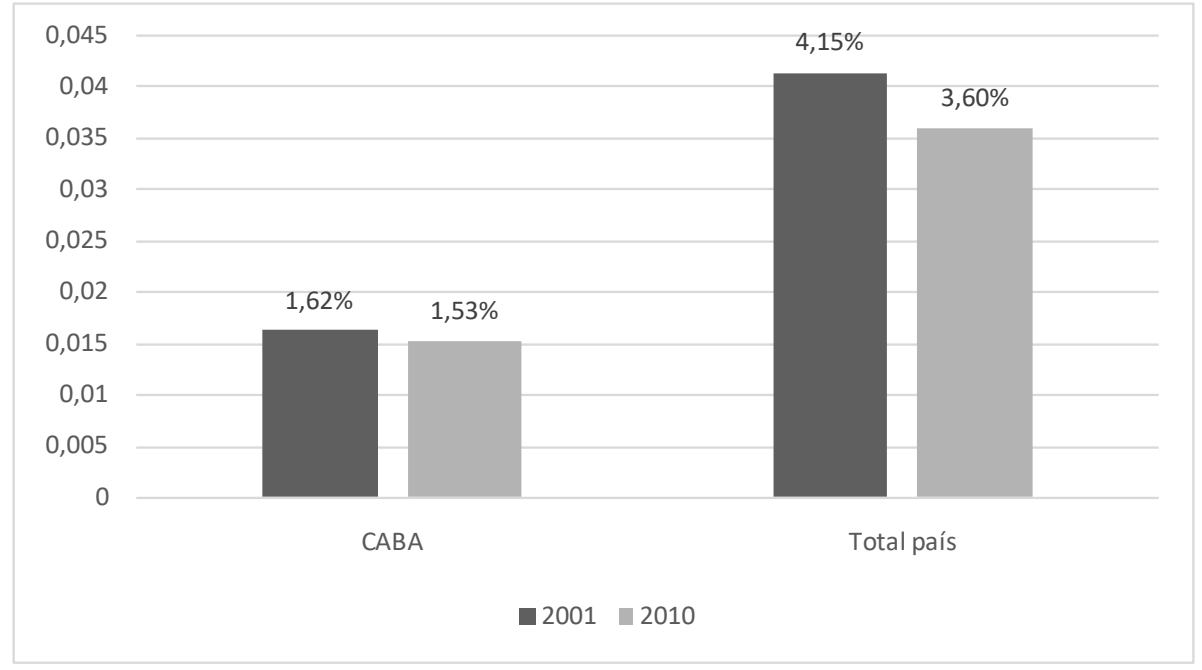

Fuente: elaboración propia en base Censo Nacional de Población, Hogares y Viviendas 2010 (INDEC).

Gráfico 9. Porcentaje de viviendas según calidad de conexión a servicios básicos. CABA y Total país. 2001 / 2010

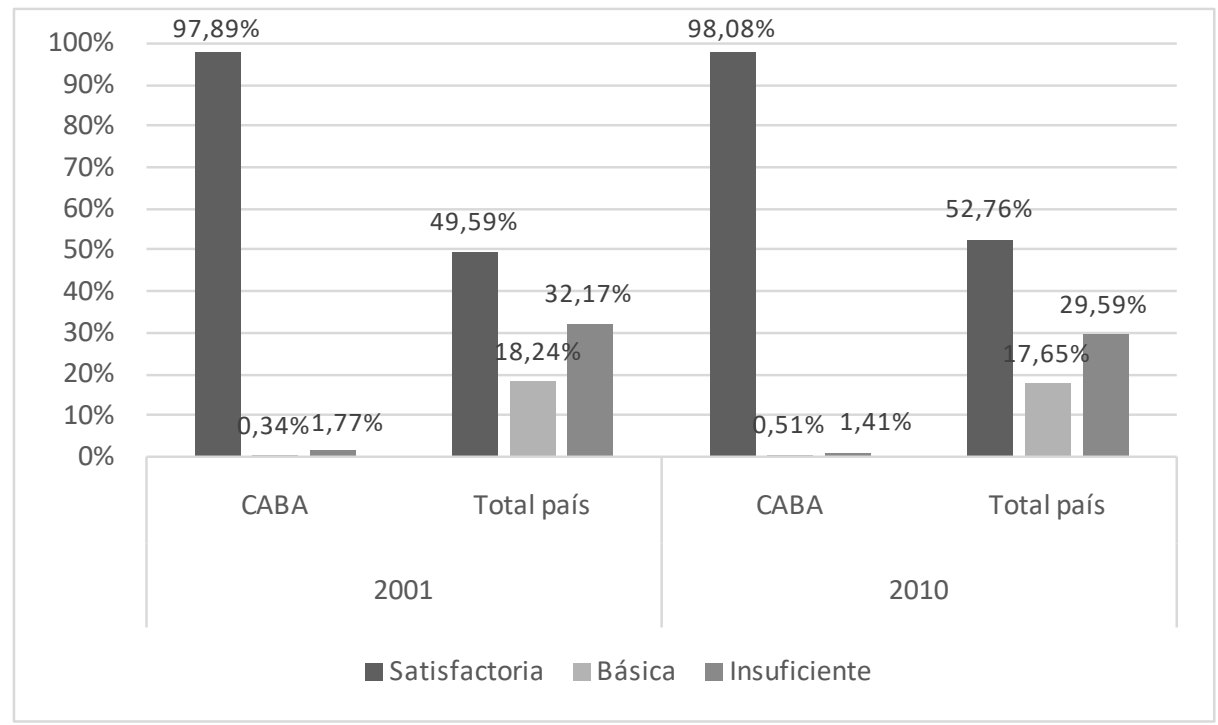

Fuente: elaboración propia en base Censo Nacional de Población, Hogares y Viviendas 2010 (INDEC). 
De este modo, es que particularmente el acceso a la vivienda, en tanto análisis del régimen de tenencia, surge como una dimensión relevante a estudiar en un contexto de condiciones habitacionales relativamente homogéneas. Como bien señala Cosacov:

En Argentina, la propiedad de la vivienda es un valor muy extendido y está fuertemente ligado a estrategias de consolidación familiar y de la propia posición social. Al mismo tiempo, ser propietario permite acceder a recursos que no tiene permitido quien no posee la propiedad que habita (Cosacov, 2012: 2).

Sin embargo, ¿qué tendencias generales se evidenciaron entre 2004 y 2015 en materia de acceso de la vivienda? Específicamente, ¿qué sucedió en la CABA? Desde la óptica del bienestar, puede trazarse una tendencia de larga data que transita desde un mayor nivel de desmercantilización de la vivienda, originada en los años $40^{18}$, hacia una progresiva mercantilización que tuvo sus inicios a finales de los años 70. Las políticas neoliberales que eliminaron los procesos de solvencia popular para el consumo y acceso a la vivienda (Pírez, 2016), continuaron manteniendo sus efectos sobre la producción de la ciudad, aun en un contexto de aplicación de políticas heterodoxas. La casi nula regulación del mercado inmobiliario por el Estado, llevó a Carmona Barrenechea y Messina (2015: 212) a caracterizar al régimen de provisión estatal de la vivienda de la ciudad como de tipo "residual". Esto implica que el Estado interviene únicamente como "rescatador de última instancia" en situaciones en las que los sujetos no pueden lograrlo por sus propios medios, como en el otorgamiento de subsidios habitacionales para la renta de habitaciones de hoteles (Gamallo, 2017: 20).

Particularmente, esta ausencia estatal se evidenció en la débil presencia de créditos hipotecarios a lo largo del período, representando en el período 2007-2011 solo un 1,3\% del PBI (Kessler, 2014: 185), situación que también se repitió en la Ciudad de Buenos Aires, en donde se aplicaron programas fragmentados y diversos de alcance limitado, bajo peso presupuestario y requisitos estrictos de acceso (Carmona Barrenechea y Messina, 2015: 224) ${ }^{19}$. Si bien las escrituras hipotecarias aumentaron en

18 Si bien aquí no se entrará en detalle, nos referimos a las políticas propias del Estado de Bienestar argentino, como la Ley de Propiedad Horizontal, la Ley de congelamiento de alquileres, las líneas subsidiadas de crédito hipotecario, el acceso al hábitat mediante loteos populares, etc. (Pírez, 2016; Yujnovsky, 1984).

19 Los programas de crédito del Gobierno del PRO en CABA, tales como "Mi primera casa" o "Mi casa BA", tuvieron un escaso impacto (Rodríguez et al., 2015: 78). 
términos absolutos, estuvieron muy lejos de los máximos alcanzados durante la década del 90, en donde llegaron a representar un 25\% del total de las actas notariales. Hacia 2012, solamente representaban un 6\% del total (CEDEM, 2012: 12-14). A su vez, la falta de regulación del mercado inmobiliario desacopló la evolución del precio de venta de las viviendas (tasadas en dólares) respecto del aumento salarial en los hogares, generando una brecha que presenta dificultades de acceso, aun por fuera de los mecanismos desmercantilizados (Cosacov, 2012: 9; Rodríguez et al., 2015: 74) ${ }^{20}$.

A partir de los datos de la Encuesta Anual de Hogares de la $C A B A$ (Gráfico 10), se observa que la proporción de hogares propietarios del universo de análisis considerado se ha ido reduciendo paulatinamente a través de los años (Cosacov, 2012: 6; Rodríguez et al., 2015: 74). Entre las puntas del período estudiado, dicha disminución fue de 14 p.p. alcanzado para el 2015, una proporción similar de hogares propietarios y no propietarios de la vivienda, evidenciándose la débil presencia de políticas habitacionales de acceso a la vivienda en el ámbito de la ciudad. A nivel comparativo con países europeos, las tasas de propietarios de viviendas de la CABA se asemejan a las halladas en países con regímenes socialdemócratas como Dinamarca y Holanda, aunque en contextos distintos, ya que en dichas naciones el sistema de alquileres públicos es fuerte, así como el mercado privado se encuentra fuertemente regulado (Kurz y Blossfeld, 2004) $)^{21}$.

20 Es necesario aclarar que el análisis de esta dimensión se realiza principalmente a nivel de la ciudad de Buenos Aires. En este sentido, no se hace referencia al programa PROCREAR de nivel nacional lanzado en 2013 que, al dirigirse a la construcción, ampliación y refacción de vivienda, tuvo poca repercusión en la ciudad. Las bajas tasas y extensión de cuotas, si permitirían pensar a dicho programa como un mecanismo de desmercantilización inmobiliaria.

21 Tal como señala Kemeny (1980), la propiedad de la vivienda se torna una solución o una vía frecuente en los regímenes individualistas, mientras que el alquiler lo es en los regímenes colectivistas. Sin embargo, como es en el caso de la CABA, la relación entre régimen de tenencia y régimen de bienestar no es necesariamente lineal. 
Gráfico 10. Distribución de hogares según régimen de tenencia de la vivienda. CABA 2004-2015 (en porcentaje)

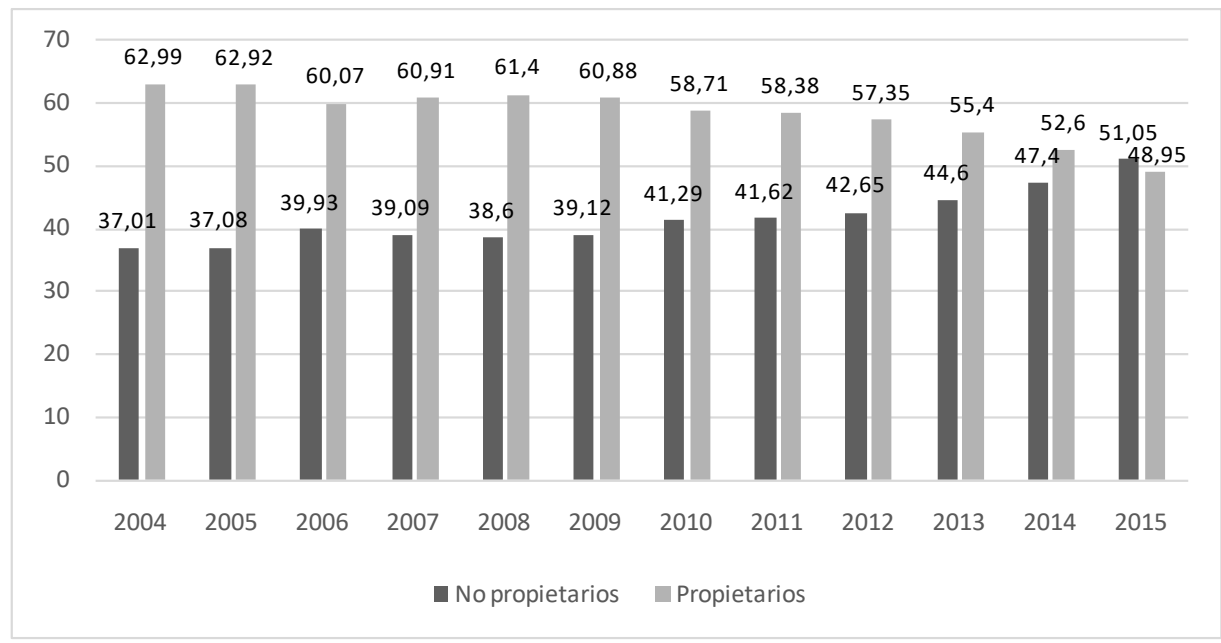

Fuente: elaboración propia en base a EAH - Dirección General de Estadística y Censos (Ministerio de Economía y Finanzas GCBA).

\subsection{LA CIUDAD DE BUENOS AIRES Y LOS SERVICIOS PÚBLICOS}

La Ciudad de Buenos Aires tiene larga trayectoria en la profesionalización de la salud, sede de la Facultad de Medicina de la Universidad de Buenos Aires y área donde se concentran hospitales de prestigio y calidad de sus prestaciones a nivel regional. Tal es así que, durante el año 2016 en la Ciudad de Buenos Aires, se realizaron un total de 8.903.404 de consultas externas en hospitales de dicho aglomerado. Del total de las consultas externas realizadas, el 71,7\% (6.383.318) se correspondieron a hospitales generales de agudos, el 18,4\% a hospitales especializados, y el porcentaje restante a hospitales de niños (9,9\%). Cabe señalar que, durante el 2015, poco más de la mitad de los pacientes que realizan dichas consultas habita la ciudad (55\%); mientras que el porcentaje restante reside en otras áreas geográficas (38,7\% Conurbano Bonaerense,6,4\% otros) (Anuario estadístico 2016, DGEyC-GCBA, 2016).

En lo que respecta a la cobertura de salud de los residentes de la ciudad, a través de la cual acceden las personas al sistema sanitario, tiende a ser mayormente vía obra social $(40,6 \%)$, seguido por un $20 \%$ que recurre al sistema público, un $19,9 \%$ se atiende sólo por prepaga o mutual vía obra social, y un 12,7\% lo hace a través de la contratación de prepaga de manera voluntaria; el 6,7\% lo hace vía otros medios (Anuario estadístico 2016, DGEyC-GCBA, 2016). A lo largo del 2017, se dio un incremento respecto al año anterior de 1,5 p.p. en la filiación 
a obras sociales $(42,1 \%)$, teniendo en cuenta que la medicina prepaga por contratación voluntaria experimentó un descenso de 1,5 p.p.; y, por otra parte, la cantidad de habitantes que se atienden por sistema público de salud desciende al 18,7\%. A su vez, quienes acceden por prepaga o mutual vía obra social aumentó 1,7 p.p. (Buenos Aires en números, DGEyC-GCBA, 2017).

No es menor hacer referencia a las estadísticas vitales de la ciudad, que resultan de los diferentes registros administrativos tales como nacimientos, defunciones y matrimonios. Uno de los indicadores más habituales es la tasa de mortalidad general, que para el año 2017 representó un 9,7\% por cada mil habitantes, porcentaje que se mantiene más o menos estable desde 2010.

Por otra parte, la tasa de mortalidad infantil en la ciudad para el mismo año es de 6,7 por mil nacidos vivos, porcentaje que se iguala a la tasa de 2010. Dicho porcentaje, si se tiene en cuenta la comuna de residencia habitual de la madre, asciende a 8,9 por mil nacidos vivos en la Comuna 8 (la cual comprende a los barrios de Villa Soldati, Villa Riachuelo y Villa Lugano). En cuanto a la tasa de mortalidad neonatal, esto es, el número de recién nacidos que fallecen antes de los 28 días de vida, por cada mil recién nacidos vivos de un año dado, representa el 4,8\% en 2017. Porcentaje que asciende a 7,1\% en la Comuna 11 (la cual comprende a los barrios de Villa General Mitre, Villa Devoto, Villa del Parque y Villa Santa Rita). Asimismo, la tasa de mortalidad posneonatal para el mismo año (relación entre las defunciones de niños con edades comprendidas entre 28 días y menos de 1 año en un año dado y los nacidos vivos del año), representa el 1,9\% en la ciudad. Otro indicador relevante es la tasa de mortalidad materna, la cual representa un $0,6 \%$ en 2017, porcentaje que se redujo a la mitad respecto del año anterior $(2016,1,3 \%)$ (Estadísticas vitales, DGEyC-GCBA).

Uno de los transportes más característicos de la Ciudad de Buenos Aires es el subterráneo, que incluye las líneas A, B, C, D, E, H y el Premetro. Durante el año 2016, el promedio diario de pasajeros transportados vía este medio fue de 1.2 millones (Anuario estadístico2016, DGEyC-GCBA, 2016). Hacia 2017, se calculó un promedio mensual de 23 millones de personas transportadas a través de los mismos (Buenos Aires en números, DGEyC-GCBA, 2017).

Por otra parte, es de gran relevancia la cantidad de líneas de colectivo que circulan por la ciudad y transportan a miles de personas a diario. Si bien no se encuentran disponibles datos del año 2016, hacia 2015 se contabilizaban 138 líneas de colectivos, entre la Ciudad de Buenos Aires y el grupo suburbano I y $\mathrm{II}^{22}$.

22 Suburbana Grupo I: una cabecera en ciudad de Buenos Aires y otra en partidos 
La Ciudad de Buenos Aires es uno de los centros turísticos más atractivos por ser la capital de la Argentina. En este sentido, cuenta con una estructura que posibilita sudesarrollo, tal es así, que cuenta con un total de 430 establecimientos hoteleros, con capacidad de alojar a 1.8 millones de pasajeros. Durante 2016, un total de 4.5 millones de viajeros visitaron la ciudad y los meses mayormente concurridos fueron julio, octubre y noviembre, evidenciado a partir de la alta tasa de ocupación de las habitaciones durante los mismos (70,3\%, 72,2\% y $75,3 \%$, respectivamente). El valor promedio de una habitación durante el año 2016, en los meses anteriormente destacados, equivalía a USD 64, valor que se aproxima al de los hoteles 4 estrellas. En cuanto a los viajeros, el 58\% residen en alguna provincia del país y visitan la ciudad, mientras que el otro $42 \%$ restante son turistas extranjeros, de los cuales mayoritariamente son brasileros, seguidos por los europeos (Buenos Aires en números, DGEyC-GCBA, 2017).

En 2016, en la Ciudad de Buenos Aires, había alrededor de 1,7 millones de usuarios de energía eléctrica, de los cuales el $86 \%$ se correspondía con el tipo de consumidor residencial. Asimismo, se consumían alrededor de 12.5 millones de MWh totales, lo que representa casi un $80 \%$ con relación a la energía que es generada. Dicho consumo se concentra mayormente en el uso residencial y comercial (Anuario estadístico 2016, DGEyC- GCBA, 2016).

En lo que respecta al servicio de gas, la ciudad cuenta con $1.4 \mathrm{mi}-$ llones de usuarios residenciales de gas, y el dispendio de metro cúbico entregado a los hogares representa poco más de un tercio del total, mientras que el resto es entregado mayoritariamente a central eléctrica, seguido por el GNC, consumidor comercial, ente oficial, industrial (Anuario estadístico 2016, DGEyC-GCBA, 2016).

El servicio de telefonía registra aproximadamente 1.7 millones de líneas instaladas, de las cuales el $83 \%$ se encuentra en servicio. En lo que refiere al acceso de internet residencial, el último dato disponible es del año 2013 registrando 3.8 millones accesos de organizaciones a internet. Otros 1.250 .000 de abonados a la TV por cable, y el servicio de recolección de residuos registró, para ese año, un total de 1 millón y medio de toneladas de residuos generados durante ese mismo año, lo que equivale a un 1,3 kg diario por habitante (Buenos Aires en números, DGEyC-GCBA, 2017).

Hacia el año 2016, se registraron un total de 2761 unidades educativas entre nivel inicial, primario, secundario y superior no universitario. Son mayoritarias las unidades educativas de tipo "común",

del Conurbano Bonaerense; Suburbana Grupo II: con recorridos de media distancia partiendo de la Ciudad de Buenos Aires. 
mientras que unidades especiales y de adultos representan un $14 \%$ del total. Asimismo, se registró un total de 757.139 matriculados para el mismo año (Anuario estadístico 2016, DGEyC-GCBA, 2016).

Independientemente de la modalidad (común o especial), para el año 2016, el nivel inicial representa el 27,6\% (761) del total de las unidades educativas y, mayoritariamente, son de gestión privada $(64,8 \%)$. $\mathrm{Si}$ se tiene en cuenta el dato administrativo que registra la cantidad de niños/as matriculados en la escuela de gestión estatal es de un total de 54.801, número que ascendió un 12,6\% respecto del que se registra para el año 2010 (48.671). Asimismo, en las escuelas de gestión privada el número de matriculados para 2016 es de 69.468 (Anuario estadístico 2016, DGEyC-GCBA, 2016).

Por otra parte, unas 1044 unidades educativas están dedicadas al nivel primario, lo que representa un 37,8\% del total. Poco más de la mitad son de gestión estatal $(55,7 \%)$ y en ellas se encuentran matriculados 154.921 niños/as o adultos. En este sentido, un 3\% están matriculados en unidades educativas de adultos, otro 1,6\% de educación especial y el porcentaje restante en unidades de educación común. Por otra parte, las escuelas privadas, cuentan con un total de 139.556 niños/as o adultos matriculados en dicho nivel (Anuario estadístico 2016, DGEyC-GCBA, 2016).

En lo que respecta al nivel secundario, son 690 unidades educativas las que cubren dicho nivel, de las cuales poco menos de la mitad son de gestión estatal. En estas se registraron, durante el 2016, un total de 132.715 matriculados, de los cuales poco menos de un tercio $(27 \%)$ se encuentran matriculados en unidades educativas de adultos; mientras que el porcentaje restante lo hacen en unidades comunes. Si bien no existen grandes diferencias con el número de matriculados que se registran en unidades privadas (99.227), sí es relevante señalar que en ellas el porcentaje de los que asisten a establecimientos educativos para adultos es de un 4,5\%.

Constan 266 unidades educativas para el nivel superior no universitario, de las cuales un $72,5 \%$ son de gestión privada y el porcentaje restante de gestión pública. El número de matriculados asciende a 106.451. Es relevante señalar que en las 73 unidades de gestión estatal hay 47.987 de estudiantes matriculados, lo que representa poco menos de la mitad del total y en un número menor de establecimientos públicos respecto de los privados. Asimismo, si se tiene en cuenta el número de matriculados por tipo de formación, el 65,5\% corresponde a formación técnico-profesional y el porcentaje restante a la carrera de docente (Anuario estadístico 2016, DGEyC-GCBA, 2016).

Finalmente, 42 instituciones universitarias tienen sede en la Ciudad de Buenos Aires. Más de la mitad son privadas, sin embargo, son las universidades públicas las que cuentan con mayor cantidad de estu- 
diantes; mientras en las instituciones públicas cursan 353.247 alumnos, en las privadas lo hacen la mitad (165.703). Del total de los estudiantes que se registran, el 58\% son mujeres. El $46 \%$ de los egresados pertenecen a la rama de las Ciencias Sociales, Economía, Derecho; la siguen egresados de las ciencias de la salud (19\%); y en las antípodas, sólo un $1 \%$ son egresados de ciencias básicas, tales como Biología, Matemática y Física y Química (Buenos Aires en números, DGEyC-GCBA, 2017).

\section{LA CONFIGURACIÓN SOCIAL DE LA CIUDAD}

La ciudad, como veremos en los capítulos siguientes, muestra fuertes heterogeneidades en su interior, con distinciones que pueden diferenciarse claramente si dividimos la misma en tres espacios sociales: el norte, el centro y el sur.

Pero, además, lo que interesa en este trabajo es apreciar a qué lugar llegan las observaciones que se desarrollarán más adelante.

Si examinamos la ciudad en torno a observar las clases ocupacionales que la delinean socialmente, lo que aparece con fuerza, en base a los datos existentes, es el fuerte peso de los trabajadores de servicio, sobre todo de establecimientos de más de 5 ocupados, el 37,3\%. Como lo vamos a ver con la Encuesta Permanente de Hogares más adelante, el peso de esta/os trabajadores/as de servicios es abrumadora, y si sumamos a los trabajadores de servicios en pequeños establecimientos, los cuenta propia profesionales y calificados, los pequeños propietarios y sus directivos, adicionando además a las/los propietarios de establecimientos más grandes. La presencia de los trabajadores industriales es muy baja.

Tabla 1. La estructura socio-ocupacional de la Ciudad de Buenos Aires. 2012-2013

\begin{tabular}{c|c}
\hline Clases ocupacionales & Porcentaje \\
\hline Clase I: propietarios $>5$ y directivos, gerentes, funcionarios de dirección & 3,9 \\
\hline Clase II: propietarios $<5$ y directivos, gerentes, funcionarios de dirección & 5,4 \\
\hline Clase III: cuenta propia profesionales/calificados & 24,6 \\
\hline Clase IV: trabajadores de servicios $>5$ & 37,3 \\
\hline Clase V: trabajadores industriales $>5$ & 4,0 \\
\hline Clase VI: trabajadores de servicios $<5$ & 12,4 \\
\hline Clase VII: trabajadores industriales $<5$ & 1,3 \\
\hline Clase VIII: cuenta propia no calificados & 11,1 \\
\hline Total & 100,0 \\
\hline
\end{tabular}

Fuente: elaboración propia en base a encuesta FONCYT 2012-2013. 
Y, por otro lado, nos vamos a encontrar con una ciudad que iremos delineando a través de estas hojas, con una configuración relativamente heterogénea. Veamos los detalles, por un lado, la Clase I de propietarios $>5$ y directivos, gerentes, funcionarios de dirección exhibe una representación mucho mayor en el norte que en el centro o sur de la ciudad, situación que también se verifica para la Clase II, que en puntos porcentuales triplica a su misma clase de la zona sur, y el doble del centro, además de estar por arriba el promedio porcentual de la clase en la Ciudad de Buenos Aires.

Por otra parte, en la Clase III, cuenta propia profesionales/calificados, la zona centro y la zona sur, tienen una mayor representación, levemente superior a la zona norte, y en promedio a la participación de dicha clase en la ciudad.

Los trabajadores de servicios, la Clase IV, donde se concentra la mayor cantidad de profesionales asalariados, y generalmente formalizados, la presentación en la zona norte es claramente mayor, superando incluso con 14 p.p. a la zona sur.

En esta zona, cordón sur, presenta relativamente una mayor proporción de trabajadores industriales manuales, Clase V, de establecimientos de más de 5 ocupados, por arriba de promedio incluso de la ciudad.

Donde todas las zonas comparten casi igual proporción de Clase VI, trabajadores de servicios de menos de 5 ocupados, situación casi parecida para la Clase VII, los y las trabajadores industriales de menos de 5 ocupados.

Pero las proporciones invertidas de representación de clase se da con la Clase VIII, los cuenta propia no calificados, donde en la zona sur, representa al 20,3\% de las y los trabajadores; caracterizados por bajas calificaciones, bajos ingresos, y sin protección. Como vemos en la tabla, menor representación en la zona centro, y mucho menos en el norte, configura claramente las heterogeneidades de la ciudad.

Tabla 2. La estructura socio ocupacional de la Ciudad de Buenos Aires según ubicación de comunas. 2012-2013

\begin{tabular}{c|c|c|c|c}
\hline \multirow{2}{*}{ Clases ocupacionales } & \multicolumn{3}{|c|}{ Zonas según comunas } & \multirow{2}{*}{ Total } \\
\cline { 2 - 4 } & Norte & Centro & Sur & \\
\hline $\begin{array}{c}\text { Clase l: propietarios }>5 \text { y directivos, gerentes, } \\
\text { funcionarios de dirección }\end{array}$ & $6,8 \%$ & $3,7 \%$ & $1,7 \%$ & $3,9 \%$ \\
\hline
\end{tabular}




\begin{tabular}{c|c|c|c|c}
\hline $\begin{array}{c}\text { Clase II: propietarios < } 5 \text { y directivos, geren- } \\
\text { tes, funcionarios de dirección }\end{array}$ & $10,1 \%$ & $4,2 \%$ & $3,5 \%$ & $5,4 \%$ \\
\hline $\begin{array}{c}\text { Clase III: cuenta propia profesionales/califi- } \\
\text { cados }\end{array}$ & $20,3 \%$ & $26,3 \%$ & $24,4 \%$ & $24,6 \%$ \\
\hline Clase IV: trabajadores de servicios > 5 & $43,2 \%$ & $38,2 \%$ & $29,7 \%$ & $37,3 \%$ \\
\hline Clase V: trabajadores industriales >5 & $2,1 \%$ & $4,2 \%$ & $7,0 \%$ & $4,0 \%$ \\
\hline Clase VI: trabajadores de servicios < 5 & $12,8 \%$ & $12,1 \%$ & $12,8 \%$ & $12,4 \%$ \\
\hline Clase VII: trabajadores industriales < 5 & $1,4 \%$ & $1,6 \%$ & $0,6 \%$ & $1,3 \%$ \\
\hline Clase VIII: cuenta propia no calificados & $3,4 \%$ & $9,7 \%$ & $20,3 \%$ & $11,1 \%$ \\
\hline Total & $100,0 \%$ & $100,0 \%$ & $100,0 \%$ & $100,0 \%$ \\
\hline
\end{tabular}

Fuente: elaboración propia en base a encuesta FONCYT 2012-2013.

Desde este inicio mostramos la Ciudad de buenos Aires que examinaremos en los próximos capítulos, pero que permite dar el primer cincelado de la obra, la fuerte presencia de actividades asalariadas de servicios, y una no menor representación de propietarios, directivos y gerentes, junto a trabajadores calificados, que muestra claramente la desindustrialización de la ciudad y la fuerte presencia de las "clases intermedias" de servicios.

Por otro lado, una fuerte heterogeneidad, donde en la zona sur se destaca la presencia de cuenta propia no calificados, ante los trabajadores de servicios en establecimientos de más de 5 ocupados en la zona centro y norte, donde allí se concentran además propietarios, gerentes y directivos. Una ciudad no tan homogénea como parece, y como tan bien la han retratado las disciplinas artísticas.

Por último, si apreciamos cómo se ha ido configurando la ciudad en los últimos años, hasta llegar al momento en que culmina nuestra investigación, podemos verla en la tabla siguiente: 
Tabla 3. Evolución de las clases ocupacionales. Ciudad de Buenos Aires 2003/2014

\begin{tabular}{|c|c|c|c|c|c|c|c|c|c|c|c|c|c|}
\hline \multirow{2}{*}{$\begin{array}{c}\text { Clases } \\
\text { ocupacionales }\end{array}$} & \multicolumn{13}{|c|}{ Año de relevamiento } \\
\hline & 2003 & 2004 & 2005 & 2006 & 2007 & 2008 & 2009 & 2010 & 2011 & 2012 & 2013 & 2014 & 2015 \\
\hline $\begin{array}{l}\text { Clase l: propieta- } \\
\text { rios }>5 \text { y direc- } \\
\text { tivos, gerentes, } \\
\text { funcionarios de } \\
\text { dirección }\end{array}$ & $5,3 \%$ & $4,2 \%$ & $5,5 \%$ & $5,6 \%$ & $6,3 \%$ & $6,8 \%$ & $6,1 \%$ & $5,7 \%$ & $5,7 \%$ & $5,3 \%$ & $4,7 \%$ & $4,9 \%$ & $5,0 \%$ \\
\hline $\begin{array}{c}\text { Clase Il: } \\
\text { propietarios < } \\
5 \text { y directivos, } \\
\text { gerentes, } \\
\text { funcionarios de } \\
\text { dirección }\end{array}$ & $4,5 \%$ & $4,1 \%$ & $3,6 \%$ & $4,0 \%$ & $4,4 \%$ & $5,3 \%$ & $4,4 \%$ & $4,2 \%$ & $4,7 \%$ & $4,5 \%$ & $4,7 \%$ & $4,7 \%$ & $4,6 \%$ \\
\hline $\begin{array}{l}\text { Clase III: cuenta } \\
\text { propia profesio- } \\
\text { nales/calificados }\end{array}$ & $12,6 \%$ & $12,4 \%$ & $11,9 \%$ & $11,5 \%$ & $12,2 \%$ & $11,8 \%$ & $14,8 \%$ & $12,8 \%$ & $11,2 \%$ & $12,4 \%$ & $12,3 \%$ & $12,3 \%$ & $12,5 \%$ \\
\hline $\begin{array}{c}\text { Clase IV: } \\
\text { trabajadores de } \\
\text { servicios }>5\end{array}$ & $40,8 \%$ & $40,0 \%$ & $40,2 \%$ & $41,9 \%$ & $42,2 \%$ & $42,1 \%$ & $40,8 \%$ & $42,7 \%$ & $44,1 \%$ & $44,2 \%$ & $44,5 \%$ & $44,3 \%$ & $44,4 \%$ \\
\hline $\begin{array}{c}\text { Clase V: } \\
\text { trabajadores } \\
\text { industriales }>5\end{array}$ & $10,5 \%$ & $10,8 \%$ & $10,6 \%$ & $10,6 \%$ & $11,2 \%$ & $11,5 \%$ & $11,5 \%$ & $12,0 \%$ & $13,8 \%$ & $13,4 \%$ & $13,6 \%$ & $13,5 \%$ & $13,2 \%$ \\
\hline
\end{tabular}




\begin{tabular}{|c|c|c|c|c|c|c|c|c|c|c|c|c|c|}
\hline $\begin{array}{c}\text { Clase VI: } \\
\text { trabajadores de } \\
\text { servicios }<5\end{array}$ & $9,4 \%$ & $9,5 \%$ & $11,4 \%$ & $10,7 \%$ & $9,2 \%$ & $8,8 \%$ & $9,0 \%$ & $8,2 \%$ & $7,4 \%$ & $7,3 \%$ & $7,4 \%$ & $7,3 \%$ & $7,2 \%$ \\
\hline $\begin{array}{c}\text { Clase VII: } \\
\text { trabajadores } \\
\text { industriales < } 5\end{array}$ & $7,3 \%$ & $10,1 \%$ & $8,4 \%$ & $6,5 \%$ & $6,1 \%$ & $6,1 \%$ & $7,0 \%$ & $7,1 \%$ & $5,9 \%$ & $6,7 \%$ & $7,1 \%$ & $7,3 \%$ & $7,2 \%$ \\
\hline $\begin{array}{l}\text { Clase VIII: cuenta } \\
\text { propia no califi- } \\
\text { cados }\end{array}$ & $9,6 \%$ & $9,0 \%$ & $8,5 \%$ & $9,3 \%$ & $8,3 \%$ & $7,6 \%$ & $6,4 \%$ & $7,4 \%$ & $7,3 \%$ & $6,2 \%$ & $5,7 \%$ & $5,7 \%$ & $5,9 \%$ \\
\hline Total & $100 \%$ & $100 \%$ & $100 \%$ & $100 \%$ & $100 \%$ & $100 \%$ & $100 \%$ & $100 \%$ & $100 \%$ & $100 \%$ & $100 \%$ & $100 \%$ & $100 \%$ \\
\hline
\end{tabular}

Fuente: elaboración propia en base a Encuesta permanente de Hogares 2003/2015 INDEC, $2^{\circ}$ Trimestres. 
A lo largo del período, desde el inicio de la "post-convertibilidad", como es definido por algunos autores (Poy y Vera, 2017; Salvia y Vera, 2013; entre otros), encontramos en la ciudad casi la misma composición de las Clases I y II, como asimismo de la Clase III, cuenta propias profesionales y calificados, pero donde encontramos los mayores cambios es en la clase asalariada de trabajadores de servicios e industriales, de establecimientos de más de 5 ocupados, donde el período fueron acrecentando cerca de 4 p.p. su representación, una leve disminución de la/os trabajadores de servicios de pequeños establecimientos, y una disminución sustantiva de la Clase VIII, cuentas propia no calificados, que pasó del período de $9,6 \%$ al 5,9\%.

Esta es la Ciudad de Buenos Aires que daremos cuenta en los capítulos siguientes.

\section{BIBLIOGRAFÍA}

Asesoría General Tutelar (ed.). (2011). Programa Ciudadanía Porteña: ¿con todo derecho?: fortalezas y debilidades de las transferencias monetarias condicionadas focalizadas en niños, niñas y adolescentes. Ministerio Público Tutelar de la Ciudad Autónoma de Buenos Aires. Buenos Aires: Eudeba.

Bermúdez, Ángeles; Carmona Barrenechea, Verónica y Royo, Laura (2015). El derecho a la alimentación en la Ciudad de Buenos Aires. Una mirada desde las políticas públicas. De Prácticas y Discursos. Cuadernos de Ciencias Sociales, vol. 4, n 5 .

Carmona Barrenechea, Verónica y Messina, Giuseppe (2015). La problemática habitacional en la ciudad de Buenos Aires desde la perspectiva de la provisión del bienestar. En Laura Pautassi y Gustavo Gamallo (eds.), El bienestar en brechas. Las políticas sociales en la Argentina de la posconvertibilidad. Buenos Aires: Biblios.

CEDEM. (2012). Cuaderno de trabajo 13. La otra cara de la construcción y el consumo: dificultades para el acceso al crédito hipotecario para la compra de viviendas en la Ciudad de Buenos Aires.

CENDA (ed.). (2010). La anatomía del nuevo patrón de crecimiento y la encrucijada actual: la economía argentina en el período 2002-2010. Argentina: Cara o Ceca.

Cosacov, Natalia (2012). Alquileres e inquilinos en la Ciudad de Buenos Aires. Una radiografía. Buenos Aires: Laboratorio de Políticas Públicas.

De la Torre, Lidia (2013). Heterogeneidades sociales en la Región Metropolitana de Buenos Aires: un sistema fragmentado que 
demanda planificación y coordinación de políticas metropolitanas. Observatorio de la Deuda Social Argentina, Barómetro de la Deuda Social Argentina, Serie del Bicentenario 2010-2016, Informe Región Metropolitana de Buenos Aires. Universidad Católica Argentina.

DGEyC-GCBA. (2013). Dinámica y envejecimiento demográfico en la Ciudad de Buenos Aires. Evolución histórica y situación reciente, Buenos Aires.

DGEyC-GCBA. (2016). Anuario estadístico 2016, Buenos Aires.

Gamallo, Gustavo (2017). La brecha de bienestar metropolitana. Asociación de Estudios Latinoamericanos, Lima.

INDEC. (2003a). ¿Qué es el gran Buenos Aires?. Instituto Nacional de Estadística y Censos (INDEC), Buenos Aires.

INDEC. (2003b). La nueva Encuesta Permanente de Hogares de Argentina.

Kemeny, Jim (1980). Home ownership and privatization. International Journal of Urban and Regional Research, 4(3), pp. 372-388.

Kessler, Gabriel (2014). Controversias sobre la desigualdad: Argentina, 2003-2013. Primera edición. Buenos Aires, Argentina: Fondo de Cultura Económica.

Kurz, Karin y Blossfeld, Hans-Peter (2004). Home ownership and social inequality in comparative perspective. Stanford, Calif: Stanford University Press.

Manrupe, Raúl y Portela, María (2001). Un diccionario de films argentinos (1930-1995), vol. 1. Buenos Aires: Corregidor.

Obradovich, Gabriel (2010). Las transformaciones de las clases medias de la Ciudad de Buenos Aires en el marco de la globalización. Documentos de Jóvenes Investigadores IIGG, 22.

Oszlak, Oscar (1988). El derecho al espacio urbano: políticas de redistribución poblacional metropolitana en un contexto autoritario. Buenos Aires: Universidad de Buenos Aires.

Oszlak, Oscar (1991). Merecer la ciudad: los pobres y el derecho al espacio urbano. Buenos Aires: Cedes.

Pírez, Pedro (2016). Buenos Aires: la orientación neoliberal de la urbanización metropolitana. Sociologías, 18(42), pp. 90-118.

Poy, Santiago y Vera, Julieta (2017). Mercado laboral, políticas sociales y desigualdad: cambios recientes en perspectiva histórica. Gran Buenos Aires (1974-2014). Economía UNAM, 14 (42), pp. 3-23.

Redondo, Nélida (2012). El envejecimiento demográfico argentino y la situación social de los adultos mayores al finalizar la primera década del siglo XXI. Población, 4(8), pp.19-30. 
Rodríguez, María Carla; Rodríguez, María Florencia y Zapata, María Cecilia (2015). La casa propia, un fenómeno en extinción. La "inquilinización" en la ciudad de Buenos Aires. Cuadernos de Vivienda y Urbanismo, 8(15), pp. 68-85.

Salvia, Agustín y Vera, Julieta (2013). Heterogeneidad estructural y desigualdad económica: Procesos intervinientes en el patrón de la distribución de los ingresos laborales del Gran Buenos Aires durante las distintas fases macroeconómicas (1992-2010). Revista Desarrollo Económico, n 207-208, vol. 52. Buenos Aires: Instituto de Desarrollo Económico y Social.

Sassen, Saskia (1998). Ciudades en la economía global: enfoques teóricos y metodológicos. EURE (Santiago), 24(71), pp. 5-25.

Sistema Integral de Coordinación de Políticas Sociales. (2017). Informe de monitoreo. Ciudadanía Porteña y Estudiar es Trabajar.

Varesi, Gastón (2011). Argentina 2002-2011: Neo-desarrollismo y radicalización progresista. Realidad económica, 264.

Velázquez, Guillermo (2007). Población, territorio y calidad de vida. En Torrado, Susana, Población y bienestar en la Argentina del primero al segundo Centenario. Buenos Aires: Edhasa.

Yujnovsky, Oscar (1984). Claves políticas del problema habitacional argentino, 1955-1981, vol. 1. Buenos Aires: Grupo Editor Latinoamericano. 